\title{
Asymptomatic Bacteriuria in Pregnant Women - Study at a Tertiary Maternity care Hospital in Hyderabad, India
}

\author{
V. Mallikarjun Rao', B.M. Shanker Venkatesh ${ }^{2 *}$ and S. Rajeshwer Rao ${ }^{3}$
}

${ }^{1}$ Department of Microbiology Shadan Medical College, Hyderabad, Telangana, India

${ }^{2}$ Department of Microbiology Osmania Medical College Hyderabad, Telangana, India

${ }^{3}$ Department of Microbiology Gandhi Medical College, Hyderabad, Telangana, India

*Corresponding author

\begin{tabular}{|l|}
\hline Ke y w or d s \\
UTI, Asymptomatic \\
bacteruria, E. coli
\end{tabular}

A B S T R A C T

Urinary Tract Infections (UTIs) commonly occurs in pregnancy, due to the morphological and physiological changes that take place in the genitourinary tract.Asymptomatic bacteriuria refers to the presence of bacteria in urine, and is a condition in which urine culture reveals a significant growth of pathogens that is greater than $10^{5}$ bacteria/ml, but without the patient showing symptoms (Gilbert et al., 2005). The apparent reduction in immunity of pregnant women appears to encourage the growth of both commensal and non-commensal microorganisms (Scott et al., 1990). The most untoward consequence of Asymptomatic bacteriuria in pregnancy is severe renal damage. Asymptomatic bacteriuria in some woman may lead to pyelonephritis or cystitis during pregnancy, while in others there may be no symptoms of urinary tract infection through-out gestation, but may develop urinary tract infection during puerperium. Pregnancy enhances the progression from asymptomatic to symptomatic bacteriuria which could lead to pyelonephritis and adverse obstetric outcomes such as prematurity, low birth weight (Connolly and Thorp, 1999) and higher fetal mortality rates (Nicolle, 1994; Delzell and Leferre, 2000). This study therefore was carried out to determine the prevalence of Asymptomatic bacteriuria (ASB) in pregnant women and to isolate, identify the causative organisms; and to test the antimicrobial susceptibility of isolated pathogens. A total of 200 pregnant women who came for ante-natal checkup in outpatient department at Govt. Maternity Hospital, Nayapool. Hyderabad were studied over a period of one year. Clean catch midstream urine sample was collected into a sterile container and then subjected to culture method. Out of 200 patients studied, significant bacteriuria was noted in $36(18 \%)$ cases and $8(4 \%)$ patients had insignificant bacteriuria. Highest incidence of 22 cases $(61.11 \%)$ were reported in the age group of 26-35 years. It was found that Asymptomatic bacteriuria showed significant increase with respect to parity, higher incidence was seen in multi gravidae $58.9 \%$ (3 and 4th parity). Incidence of Asymptomatic bacteriuria was found to decrease with the increase in gestation time, maximum number were noted in first trimester $19(52.78 \%)$ followed next by second trimester $13(36.11 \%)$ and in third trimester $4(11.11 \%)$. E. coli $20(55.56 \%)$,was the most common etiological agent followed by Klebsiella spp in 9 cases (25\%) Coagulase negative Staphylococcus in 2 cases $(5.56 \%)$ and Pseudomonas spp in 2 cases (5.56\%), Proteus mirabilis and Enterobacter, Staphylococcus aureus each in one case $(2.78 \%)$ all the strains were sensitive to imipenem and meropenem. As asymptomatic bacteriuria is associated with complications in pregnancy, it is therefore imperative that pregnant women be screened for bacteriuria, periodically in every trimester of the gestational period. Routine urine culture tests should be carried out for all antenatal women to detect asymptomatic bacteriuria, and every positive case should be treated with appropriate antibiotic therapy, to prevent any obstetric complication which is associated with pregnancy. In view of changing patterns of bacterial resistance to common drugs, the importance of educating physicians on use of antibiotics accordingly to provide empirical therapy is important. 


\section{Introduction}

Prevalence of bacteriuria is common in women due to short urethra, and easy contamination of urinary tract with fecal flora (Girishbabu et al., 2011; Kerure et al., 2013) and it increases with age and/or sexual activity.

Urinary Tract Infections (UTIs) commonly occurs in pregnancy, due to the morphological and physiological change that take place in genito urinary tract.

Urinary tract infection is of two types, symptomatic and asymptomatic. Asymptomatic Bacteriuria (ASB) is defined as the presence of actively multiplying \& persistently appearing bacteria, which is greater than $10^{5} / \mathrm{ml}$ of urine within the urinary tract, excluding the distal urethra, at a time when the patient has no symptoms of a UTI (Jayalakshmi and Jayaram, 2008). ASB can be found in both pregnant and non-pregnant women.

When comparing the same age group females the pregnant women are more commonly affected than non-pregnant females (Chandel et al., 2012; Enayat et al., 2008). This is due to urinary stasis, progesterone effect in pregnancy, decrease in urine concentration and development of glucosuria in about $70 \%$ of pregnant women which encourages bacterial growth in the urine (Patterson and Andrriole, 1987; Lucas and Cunningham, 1993) and also due to apparent reduction in immunity, different morphological and physiological changes occurring during pregnancy. All of which contribute to the development of UTI.

The prevalence of ASB was found to be 2$11 \%$ in pregnant women. As per western literature prevalence of asymptomatic bacteriuria (ASB) among pregnant women, varies from 2 to $10 \%$ (Kerure et al., 2013; Enayat et al., 2008). In Indian studies the reported prevalence rate is as high as $8 \%$ (Balamurugan et al., 2012; Patel et al., 2005; Delzell and Lefevre, 2000). Pregnancy enhances the progression from ASB to symptomatic bacteriuria and in $25 \%$ of culture positive cases, undetected and untreated ASB may lead to symptomatic infection during that pregnancy, and this may lead to acute pyelonephritis in $20-50 \%$ of cases and to adverse obstetric outcomes such as prematurity, postpartum hypertensive disease, anaemia, and higher foetal mortality rates (Connolly and Thorp, 1999; Nicolle, 1994; Delzell and Leferre, 2000). In order to prevent mother and child from any form of complication that may arise due to undiagnosed asymptomatic bacteriuria routine culture screening for all pregnant women attending antenatal clinic (Kirklam et al., 2005) has become mandatory Thus, urine culture is the gold standard screening technique for ASB which occurs during pregnancy (Patterson and Andrriole, 1987; Gayathree et al., 2010). Therefore, the most common causative agents should be investigated and communities should be made aware of their local antimicrobial resistances. The objective of this study was to identify the prevalence of ASB, its most common causative microorganisms and the antibacterial susceptibilities of the isolated microorganisms among pregnant women who attended tertiary care centre at Govt. Maternity hospital at Hyderabad, Telangana India.

\section{Materials and Methods}

This was a retrospective study conducted in the Department of Microbiology at Govt. Maternity hospital at Hyderabad, over a period of one year

Study Population: Study was conducted after getting clearance from the institutional ethical 
committee. A total of 200 pregnant women who attended antenatal clinic were included in this study.Verbal informed consent was obtained from each patient prior to sample collection. Socio-demographic data were obtained by means of personal interviews.

\section{Exclusion criteria}

1) Symptoms suggestive of infections in urinary tract (dysuria, frequency and urgency) 2) History of antibiotic therapy in previous two weeks 3) Known congenital anomalies of urinary tract. 4) History of fever 5) Pregnancy induced hypertension; and 6) Pregnancy with Diabetes Mellitus.

\section{Specimen collection and processing}

Clean-catch midstream urine was collected from each patient into a sterile universal container that were covered with tight-fitting lids. Urine samples of each patient was centrifuged at $3000 \mathrm{rpm}$ for $10-15$ minutes, the supernatant was discarded and the deposit examined microscopically at high magnification for pus cells, red blood cells, epithelial cells, casts, crystals, yeast-like cells and Trichomonas vaginalis. The samples were processed within one hour of collection, by using standard microbiological procedures. Samples were cultured on dried plates of Sheep blood agar (in 5-10\% CO2 atmosphere), MacConkey's agar and cysteine lactose electrolyte deficient agar (CLED), using a calibrated drop delivering $0.002 \mathrm{ml}$ of urine by standard loop method and the plates were incubated aerobically at $37^{\circ} \mathrm{C}$ overnight. Prolonged incubation was done for further 24hours if no growth obtained. The identification of organisms was done by Gram staining, motility test, catalase test, oxidase test, coagulase test, and routine biochemical tests as per Cowan and Steels Manual (Cowan and Steels manual for the identification of medical bacteria, 1993). The growth was interpreted as- sterile if no growth obtained. Culture results were interpreted as significant and insignificant according to the standard criteria. Colony counts yielding bacterial growth of $10^{5} / \mathrm{CFUs} \mathrm{ml}$ or more of pure isolates were regarded as significant for infection Insignificant growth was reported if colony count was less than $10^{5}$ CFUs per $\mathrm{ml}$. The standardized Kirby-Bauer disc diffusion method on Muller Hinton agar plate of the Clinical and Laboratory Standards Institute (formerly NCCLS) was used for antibiotic susceptibility testing and interpretations were carried out accordingly (Clinical and Laboratory Standards Institute, 2007).

The antibiotics which were tested were : amikacin (30 mcg); gentamycin (30 mcg); Cefuroxime $(30 \mathrm{mcg})$; ceftazidime $(30 \mathrm{mcg})$; cefotaxime (30 mcg); Cefepime (30mcg) : ceftriaxone (30mcg); Ciprofloxacin $(5 \mathrm{mcg})$ : moxifloxacin (5mcg): ofloxacin (5mcg); sparfloxacin (5mcg): tobramycin (10mcg); gatifloxacin (10mcg); Imipenem (10mcg), Meropenem (10mcg), nitrofurantoin; clindamycin $(2 \mathrm{mcg})$, Co-trimaxozole $(25 \mathrm{mcg})$; Lincomycin $(15 \mathrm{mcg})$; cefdroxil.

All the above antibiotic discs were obtained from HiMedia (Mumbai, India), and Bio-Rad, New Delhi, India.

\section{Results and Discussion}

Among 200 asymptomatic pregnant women who were screened, significant bacteriuria was found in only $36(18 \%)$ cases and insignificant bacteriuria in $8(4 \%)$ cases. 156 samples were sterile with no growth (Table 1).

In our study, 22 cases $(61.11 \%)$ were reported in the age group of 26-35 years, which is the highest incidence, next highest of $10(27.78 \%)$ cases were seen in 18-25 years group \& 04 casess $(11.11 \%)$ were seen in the age group of more than 36years (Table 2). 
The prevalence of asymptomatic bacteriuria showed significant increase with respect to parity, higher incidence was seen in multigravidae $58.3 \%$ (Table 3).

In our study, it was found that among positive cultures incidence of significant bacteruria has a relation with gestational period,maximum number were noted in first trimester 19 $(52.78 \%)$ followed next by second trimester $13(36.11 \%)$ and third trimester $4(11.11 \%)$ (Table 4).

The uropathogens which were isolated in culture were Escherichia coli in 20 patients $(55.56 \%)$ the most predominant organism, followed by Klebsiella pneumoniae in 09 cases (25\%) Coagulase negative Staphylococcus in 2 cases (5.56\%), and Pseudomonas spp 02 cases (5.56), Staphylococcus aureus, Proteus mirabilis and Enterobacter spp. each in one case $(2.78 \%)$ (Table 5).

Escherichia coli, the most common isolate, was found to be almost $100 \%$ sensitive to the Carbapenems - Imipenem, and Meropenem, $4^{\text {th }}$ generation cephalosporin - Cefepime showed 95\% sensitivity (Table 6).

Similar sensitivity (90\%) was also recorded against Aminoglycosides like Amikacin and Gentamycin, cefuroxime $2^{\text {nd }}$ generation cephalosporin showed $80 \%$, sensitivity and Furantoins - Nitrofurantoin documented $75 \%$ sensitivity, while other cephalosporins like Cefatazidime (20\%), Cefotaxime (10\%), Quinolines like Gatifloxacin (40\%), ciprofloxacin (30\%), exhibited varied sensitivity.

Klebsiella pneumoniae, the second most frequent organism, showed almost $100 \%$ sensitivity to carbapenems - imipenem, meropenem, and cephalosporins like: cefepime and cefuroxime. Sensitivity to amikacin and ofloxacin was $77.8 \%$ while for ceftriaxone it was $66.7 \%$. Pseudomonas spp. showed $100 \%$ sensitivity to cefoperazone, ceftazidime and cefipime.

Gram positive cocci showed good sensitivity to imipenem, meropenem, clindamycin, Lincomycin and cefdroxil.

The overall antimicrobial susceptibility pattern showed broad spectrum carbapenems imipenem, and meropenem to be the most effective antibiotics.

In females urinary tract infections are common and in pregnancy due to the morphological and physiological changes that takes place in the genitourinary tract, infection is much more common (Kerure et al., 2013; Patel et al., 2005) One of the important causative factors for premature or low birth infants, postpartum urinary tract infections and higher fetal mortality rates in pregnant women is Asymptomatic bacteriuria. Women who have bacteriuria have a 20-50 fold increased risk of developing pyelonephritis as compared to women who do not have bacteriuria (Celen et al., 2011; Kacmaz et al., 2006) Asymptomatic bacteriuria of pregnancy needs special attention, due to lack of symptoms and its adverse consequences in pregnancy.

In this study, the prevalence of asymptomatic bacteriuria was $18 \%$, which was similar to those seen in various other studies by (Girishbabu et al., 2011; Kerure et al., 2013; Balamurugan et al., 2012; Patel et al., 2005; Celen et al., 2011; Kass, 1960).

The incidence in various Indian studies (Yashodhara et al., 1987) was found to be between 5 and $12 \%$, and in Western studies (Kerure et al., 2013), the incidence ranges from $2-7 \%$. The incidence of ASB was $8.4 \%$ in a south Indian population by a study by (Lavanya and Jogalokshmi, 2002; Neupane et al., 2012) (26\%) and (Imade et al., 2010) $(45.3 \%)$ reported a higher prevalence. 
Table.1 Showing culture interpretation of total cases screened (200)

\begin{tabular}{|l|c|c|}
\hline \multicolumn{1}{|c|}{ Culture interpretation } & Number of cases & Per centage \\
\hline Significant bacteriuria & 36 & $18 \%$ \\
\hline Insignificant bacteriuria & 8 & $4 \%$ \\
\hline Sterile with no growth. & 156 & $78 \%$ \\
\hline
\end{tabular}

Table.2 Showing age distribution of culture positive cases

\begin{tabular}{|c|c|c|}
\hline Age Group & Number of cases & Per centage \\
\hline $18-25$ years & 10 & $27.78 \%$ \\
\hline 26-35 years & 22 & $61.11 \%$ \\
\hline More than 36 yrs & 04 & $11.11 \%$ \\
\hline
\end{tabular}

Table. 3 Showing distribution of parity of culture positive case

\begin{tabular}{|l|c|c|}
\hline \multicolumn{1}{|c|}{ PARITY } & Number of cases & Per centage \\
\hline Multigravida & 21 & $58.33 \%$ \\
\hline Primie & 15 & $41.64 \%$ \\
\hline
\end{tabular}

Table.4 Showing Gestational distribution of culture positive cases

\begin{tabular}{|l|c|c|}
\hline \multicolumn{1}{|c|}{ Trimester } & Number of cases & Per centage \\
\hline first trimester & 19 & $52.78 \%$ \\
\hline second trimester & 13 & $36.11 \%$ \\
\hline third trimester & 4 & $11.11 \%$ \\
\hline
\end{tabular}

Table.5 Showing per centage distribution of isolated organism among culture positive cases

\begin{tabular}{|l|c|c|}
\hline \multicolumn{1}{|c|}{ Organism isolated } & Isolated Number. & Per centage \\
\hline Escherichia coli & 20 & $55.56 \%$ \\
\hline Klebsiella & 09 & $25 \%$ \\
\hline Pseudomonas spp & 02 & $5.56 \%$ \\
\hline Coagulase & 02 & $5.56 \%$ \\
\hline Staphylococcus & & \\
\hline Staphylococcus aureus & 01 & $2.78 \%$ \\
\hline Enterobacter spp & 01 & $2.78 \%$ \\
\hline Proteus mirabilis & 01 & $2.78 \%$ \\
\hline
\end{tabular}


Table.6 Showing antibiotic sensitivity pattern of isolated organism among culture positive cases

\begin{tabular}{|l|l|l|l|l|l|l|l|}
\hline Anti & $\begin{array}{l}\text { E.coli } \\
(20)\end{array}$ & $\begin{array}{l}\text { Kleb } \\
(09)\end{array}$ & $\begin{array}{l}\text { Pseudo } \\
(02)\end{array}$ & $\begin{array}{l}\text { St.epi } \\
(02)\end{array}$ & $\begin{array}{l}\text { Enterobacter } \\
(01)\end{array}$ & $\begin{array}{l}\text { Prote } \\
(01)\end{array}$ & $\begin{array}{l}\text { St.aureus } \\
(01)\end{array}$ \\
\hline AMK & $18(90 \%)$ & $7(77.8 \%)$ & 0 & NT & $1(100 \%)$ & $1(100 \%)$ & NT \\
\hline GEN & $18(90 \%)$ & $5(55.5 \%)$ & $02(100 \%)$ & NT & NT & NT & NT \\
\hline CXM & $16(80 \%)$ & $09(100 \%)$ & NT & NT & 0 & $1(100 \%)$ & NT \\
\hline CTZ & $4(20 \%)$ & $1(11 \%)$ & $2(100 \%)$ & NT & 0 & 0 & NT \\
\hline CTX & $2(10 \%)$ & $6(66.7 \%)$ & $1(50 \%)$ & NT & 0 & 0 & NT \\
\hline CPM & $19(95 \%)$ & $09(100 \%)$ & $2(100 \%)$ & NT & $1(100 \%)$ & $1(100 \%)$ & NT \\
\hline CTR & $9(45 \%)$ & 0 & 0 & NT & $1(100 \%)$ & $1(100 \%)$ & NT \\
\hline CIP & $6(30 \%)$ & $2(22 \%)$ & $1(50 \%)$ & NT & $1(100 \%)$ & $1(100 \%)$ & NT \\
\hline MOX & $8(40 \%)$ & $4(44 \%)$ & NT & NT & 0 & 0 & NT \\
\hline OFL & $10(50 \%)$ & $7(77.8 \%)$ & $1(50 \%)$ & NT & 0 & 0 & NT \\
\hline SPA & $10(50 \%)$ & $5(55.5 \%)$ & 0 & NT & 0 & 0 & NT \\
\hline TOB & $1(05)$ & $2(22 \%)$ & 0 & NT & 0 & 0 & NT \\
\hline GTX & $8(40 \%)$ & $6(66.7 \%)$ & NT & NT & 0 & 0 & NT \\
\hline IPM & $20(100)$ & $09(100)$ & $2(100)$ & NT & $1(100 \%)$ & $1(100 \%)$ & NT \\
\hline MEM & $20(100)$ & $08(88.8 \%)$ & $2(100)$ & NT & $1(100 \%)$ & $1(100 \%)$ & NT \\
\hline NTF & $15(75 \%)$ & $4(44.4 \%)$ & $1(50 \%)$ & NT & $1(100 \%)$ & $1(100 \%)$ & NT \\
\hline CD & NT & NT & NT & $2(100 \%)$ & NT & NT & $1(100 \%)$ \\
\hline COT & NT & NT & NT & $2(100 \%)$ & NT & NT & $1(100 \%)$ \\
\hline LM & NT & NT & NT & $2(100 \%)$ & NT & NT & $1(100 \%)$ \\
\hline CFD & NT & NT & NT & $2(100 \%)$ & NT & NT & $1(100 \%)$ \\
\hline
\end{tabular}

AMK: amikacin; GEN: gentamycin CXM: Cefuroxime CTZ: ceftazidime; CTX: cefotaxime; CPM: Cefepime CTR: ceftriaxone; CIP: Ciprofloxacin MOX: moxifloxacin OFL: ofloxacin SPA: sparfloxacin TOB: tobramycin; GTX: gatifloxacin; IPM: Imipenem, MEM - Meropenem, NTF: nitrofurantoin; CD: clindamycin COT: Co-trim LM: Lincomycin CFD: cefdroxil

In studies conducted by Maryam Kasraeian et al., (2009) and Ansari and Rajkumari (2001) incidence rate among pregnant women correlates with the present study (Verma et al., 2016; Jain et al., 2013) This high prevalence is attributed to their socioeconomic status, lack of personal and environmental hygiene. There was significant association between presence of bacteriuria and certain risk factors like, low socioeconomic class, lower education level and multiparty (Tahir, 2015).

This variation may be explained by the fact that there were differences in the environment, social habits of the community, socio-economic status, the standards of personal hygiene and education among the patients who were studied. As the prevalence of ASB is $18 \%$ in our study screening of all antenatal women for ASB, especially in early pregnancy by quantitative urine culture is recommended.

In our study incidence of ASB was more in multigravida $58.33 \%$ this is similar to study by Girishbabu et al., (2011) and Qudsia (2011).

In this study, age group of 26-35 years had the highest percentage of infection $(61.11 \%)$, followed by age group of 18-25 years 
(27.78\%) and this was closely followed by age group more than 36 years $(11.11 \%)$. This is similar to the study done by $\mathrm{Al}$ Senani (2011) and Sudha Biradar et al., (2013) also reported majority of the women in the age group of 26-35 years. The observed trend of bacteriuria in this study and reports from other studies showed that the age range of 2140 years served as the high risk group for development of UTIs in pregnant women. This high incidence of ASB in the young reproductive age group is due to early marriage and childbearing in our country, especially in the rural sector. Turpin et al., (2007) reported a higher prevalence of ASB in pregnant women who were aged 35-39 years. Many studies show advancing age as a risk factor for acquiring ASB in pregnancy because there is decrease in glycogen deposition and reduction in the lactobacillus as a part of ageing process which enhances bacterial adherence and invasion by pathogens and make them more susceptible (Sudha Biradar et al., 2013).

In this study, incidence of asymptomatic bacteriuria was higher in multigravidae $(58.33 \%)$, which was similar to study done by Okonko et al., (2010), Roy et al., (1974), Verma et al., (2016) and Sujatha and Manju Nawani (2013). The higher incidence of ASB in the multigravida is due to increased colonization of urinary tract by pathogens due to repeated exposure to urinary stasis or previous infections.

In our study the prevalence of asymptomatic bacteriuria showed variation with gestational age, a higher rate of infection was detected in first trimester of pregnancy, which was similar to that seen in the study of Yashodara et al., (1987).

The higher incidence in first trimester could be caused by hormonal changes occurring prior to occurrence of anatomical changes Turpin et al., (2007) reported a high percentage of asymptomatic bacteriuria in the first and early second trimesters of pregnancy. Nath et al., (1996) and Roy et al., (1974) detected higher rate of infection in second trimester. This may be attributed to pregnant women reporting at the antenatal clinic usually during this period.

The most prevalence organism observed in this study was Escherichia coli (55.56\%), followed by Klebsiella species (25\%). The other organisms isolated included, Pseudomonas aeruginosa (5.56\%). Coagulase negative Staphylococcus (5.56\%), Proteus species (2.78\%), Staphylococcus aureus (2.78\%), and Enterobacter spp (2.78\%). The bacteria which are responsible for asymptomatic bacteriuria are of faecal origin, which colonize the periurethral area. The same predominant trend of Escherichia coli infection pattern was also shown by different studies done by Girishbabu et al., (2011), Chandel et al., (2012), Enayat et al., (2008), Imade et al., (2010), Jain et al., (2013) and Senthinath et al., (2013). This could be due to the fact that most Escherichia coli strains prefer the environment of urinary stasis seen commonly in pregnancy, and another reason could be as a result of poor genital hygienic practices during defecation and micturition by pregnant women.

In this study, most of the isolates showed $100 \%$ sensitivity to imipenem and meropenem. Among the aminoglycosides, amikacin showed good sensitivity. While some of the cephalosporins also showed good sensitivity. This is in line with the study done by Sujatha and Manju Nawani (2013).

Gram positive microorganisms which were isolated showed good sensitivity to imipenem, meropenem, clindamycin, Lincomycin, and cefdroxil Antibiogram in this study correlated with that of study by Enayat et al., (2008). The antimicrobial sensitivity and resistance pattern vary from community to community 
and from hospital to hospital, this upsurge in antibiotic resistance patterns could have been caused by emergence of resistant strains, which may be due to indiscriminate use of antibiotics. Its abuse, self-medication, also low costs and availability of drugs over the counter could be other factors contributing to antibiotic resistance.

As asymptomatic bacteriuria is associated with complications in pregnancy, it is therefore imperative that pregnant women be screened for bacteriuria, periodically in every trimester of the gestational period. Early screening and appropriate treatment with susceptible antibiotic during antenatal period helps in reducing the incidence of pyelonephritis.It is important also to educate treating doctors, regarding empirical use of antibiotics in view of changing patterns of bacterial resistance to common drug. Age, parity, medical or obstetrical high risk factors all play a role in causing urinary tract infection and adverse perinatal outcome and maternal morbidity as seen in our study.Further studies are needed to conclude that asymptomatic bacteriuria can lead to adverse perinatal or maternal outcomes. Thus, we conclude that early prenatal screening of women for urinary tract infection and treatment of women prevents pyelonephritis and helps in reducing adverse maternal outcomes.

\section{Funding}

No funding sources Conflict of interest: None declared Ethical approval: The study was approved by the Institutional Ethics Committee.

\section{References}

Al Senani NS. Asymptomatic bacteriuria in pregnant women. Bahrain Med Bull. 2011; 33: 1-4.
Ansari HQF, and Rajkumari A. Prevalence of asymptomatic bacteriuria and associated risk factors among antenatal women attending a tertiary care hospital. J Med Allied Sci. 2001; 1(2): 74-8.

Balamurugan S, Chaitanya Shah, Jayapriya S., Priyadarshini S., Jeya M., Ramesh Rao K. Reagent strip testing (RST) for Asymptomatic bacteriuria (ASB) in pregnant women: A cost-effective screening tool in under-resourced settings. JCDR 2012 May; 6: 671-673.

Celen S, Oruc AS, Karayalcin R, Saygan S, Unlu S, Polat B, et al., Asymptomatic Bacteriuria and Antibacterial Susceptibility Patterns in an Obstetric Population. ISRN Obstet Gynaecol. 2011; 2011 Article ID 721872.

Chandel R, Kanga A, Thakur K, Mokta KK, Sood A, Chauhan S. Prevalence of pregnancy associated asymptomatic bacteriuria: A study done in a tertiary care hospital. J Obstet Gynaecol India. 2012; 62(5): 511-4.

Clinical and Laboratory Standards Institute. Performance standards for antimicrobial susceptibility testing: 17th informational supplement. CLSI / NCCLS document M100-S17. Clinical and laboratory Standards Institute, Wayne, Pennsylvania; 2007: 27(1).

Connolly A, and Thorp JM., Jr Urinary tract infection in pregnancy. Urol Clin North Am. 1999; 26(4): 779-787.

Cowan and Steels manual for the identification of medical bacteria. In: Barrow GI, Feltham RKA, editors. 3rd ed. Cambridge: Cambridge University Press; 1993.

Delzell JE, and Lefevre ML. Urinary tract infections during pregnancy. Am Fam Physician 2000; 61: 713-21.

Delzell JE, Jr, and Leferre ML. Urinary tract infections during pregnancy. Am Fam Physician. 2000; 61(3): 713-721. 
Enayat K, Fariba F, Bahram N. Asymptomatic bacteriuria among pregnant women referred to out patient clinics in Sanandaj, Iran. Int Braz J Urol.2008; 34(6): 699-707.

Enayat K, Fariba F, Bahram N. Asymptomatic bacteriuria among pregnant women referred to outpatient clinics in Sanandaj, Iran. Int Braz J Urol. 2008; 34(6): 699-707.

Gayathree L, Shetty S, Deshpande SR, Venkatesh DT. Screening for asymptomatic bacteriuria in pregnancy: An evaluation of various screening tests in Hassan District Hospital, India. J Clin Diagn Res. 2010; 4(4): 2702-6.

Gilbert DN, Moelleving RC, Jr, Eliopoulos GN, Sande NA. Sanford guIde to Antimicrobial therapy. 32nd ed. Hyde Park, Vermont: Antimicrob. Therapy, Inc; 2005. pp. 22-23.

Girishbabu R J, Srikrishna R, Ramesh S T. Asymptomatic bacteriuria in pregnancy. Int J Biol Med Res 2011; 2(3); 740-742.

Imade PE, Izekor PE, Eghafona NO, Enabulele OI, Ophori E. Asymptomatic bacteriuria among pregnant women. $\mathrm{N}$ Am J Med Sci. 2010; 2(6): 263-6.

Jain V, Das V, Agarwal A, Pandey A. Asymptomatic bacteriuria and obstetric outcome following treatment in early versus late pregnancy in north Indian women. The Indian Journal of Medical Research. 2013; 137(4): 753.

Jayalakshmi J, and Jayaram VS. Evaluation of various screening tests to detect asymptomatic bacteriuria in pregnant women. Indian $\mathbf{J}$ Pathol Microbiol. 2008; 51(3): 379-81.

Kacmaz B, Cakir O, Aksoy A, Biri A. Evaluation of rapid urine screening tests to detect asymptomatic bacteriuria in pregnancy. Jpn J Infec Dis. 2006; 59(4): 261-3.

Kasraeian M. Prevalence of asymptomatic bactetiuria among pregnant women in
Shiraz, Iran. Saudi Med J. 2009; 30(7): 917-20.

Kass EH. Bacteriuria and pyelonephritis of pregnancy. Arch Intern Med. 1960; 105: 194-8.

Kerure SB, Surpur R, Sagarad SS, Hegadi S. Asymptomatic bacteriuria among among pregnant women. Int J Reprod Contracept Obstet Gynecol 2013; 2: 213-216.

Kerure SB, Surpur R, Sagarad SS, Hegadi S. Asymptomatic bacteriuria among pregnant women. Int $\mathrm{J}$ Reprod Contracept Obstet Gynecol 2013; 2: 213-216

Kirklam C, Harris S, Grzybowski Evidencebase prenatal care: part II. Thirdtrimester care and prevention of infectious diseases. Am Fam Physician. 2005; 71: 1555-1560.

Lavanya SV, and Jogalokshmi D. Asymptomatic bacteriuria in antenatal women. Int J Med Microbiol. 2002; 20(2): 105-6.

Lucas MJ, and Cunningham FG. Urinary tract infection in pregnancy. Clinical Obstet. Gynaecol. 1993; 36: 555-568.

Nath G, Chaudhary M, Prakash J, Pandey LK, Singh TB. Urinary tract infection during pregnancy and foetal outcome. Indian $\mathbf{J}$ Med Microbiol. 1996; 14: 158-60.

Neupane MS, Dhakal KS, Neupane HC, Adhikari S, Aryal B. Asymptomatic Bacteriuria among Pregnant Women attending the Outpatient Clinics of Chitwan Medical College teaching hospital in Chitwan, Nepal. IRJP. 2012; 3(11): 78-80.

Nicolle LE. Screening for asymptomatic bacteriuria in pregnancy. Ottawa Health, Canada: Canadian guide on preventive health care; 1994. pp. 100106.

Okonko IO, Ijandipe LA, Ilusanya AO, Donbraye Emmanuel OB. Detection of Urinary Tract Infection (UTI) among 
pregnant women in Oluyoro Catholic Hospital, Ibadan, South-Western Nigeria. Malaysian Journal of Microbiology. 2010; 6(1): 16-24.

Patel HD, Livsey SA, Swann RA, Bukhari SS. Can urine dipstick testing for urinary tract infection at the point of care reduce the laboratory workload? J Clin Pathol 2005; 951-54.

Patterson TF, and Andrriole VT. Bacteriuria in pregnancy. Infect Dis Clin North Am. 1987; 1: 807-822.

Qudsia H. Prevalance of asymptomatic bacteruria and associated risk factors among antenatal women attending a tertiary care hospital. J Med Allied Sci. 2011; 1(2): 74-8.

Roy SK, Sinha GR, Qudros MA. A study of bacteriuria in pregnancy. J Obstet Gynecol India. 1974; 24: 244-51

Scott JR, Whitehead ED, Naghes HM. Dan Forty Obsetrics and Gynaecology. 6th ed. Boston: McGraw Hill; 1990. pp. 60 80.

Senthinath TJ, Rajalaksmi PC, Keerthana R, Vigneshwari RS, Revathi RS, Prabhu N, et al., Prevalence of asymptomatic bacteriuria among antenatal women in rural tertiary care hospital, Tamilnadu, India. Int J Curr Microbiol App Sci. 2013; 2(1): 80-5.

Sudha Biradar K, Rajeshwari S, Sheela S Sagarad, Sneha Hegadi. Asymptomatic bacteriuria among pregnant women. Int J Reprod Contracept Obstet Gynecol. 2013; 2(2): 213-6.
Sujatha, R., and Manju Nawani - Prevalence of Asymptomatic Bacteriuria and its Antibacterial Susceptibility Pattern Among Pregnant Women Attending the Antenatal Clinic at Kanpur, Indian Journal of Clinical and Diagnostic Research: May 2013.

Tahir S. Prevalence of Asymptomatic Bacteriuria, Associated Risk Factors and Adverse Fetomaternal Outcome among Antenatal women attending a tertiary care hospital. Department of Gynae Obs, Shalamar Teaching Hospital, Lahore. 2015; 9(4): 1399-402.

Turpin CA, Minkah B, Danso KA, Frimpong EH. Asymptomatic bacteriuria in pregnant women at-tending antenatal clinic at komfo anokye teaching hospital, Kumasi. Ghana Medical Journal. 2007; 41(1): 26-9.

Verma A et al., Int J Reprod Contracept Obstet Gynecol. 2016 Dec; 5(12): 43904396 International Journal of Reproduction, Contraception, Obstetrics and Gynecology Volume 5 - Issue 12 Page 4395.

Verma A, Baheti S, Sharma M. Asymptomatic bacteriuria in pregnancy and its relation to perinatal outcome. Int J Reprod Contracept Obstet Gynecol 2016; 5: 4390-6.

Yashodhara P, Mathur R, Raman I. Urinary tract infection in pregnancy. Indian $\mathrm{J}$ Med Res. 1987; 86: 309-14.

\section{How to cite this article:}

Mallikarjun Rao, V., B.M. Shanker Venkatesh and Rajeshwer Rao, S. 2018. Asymptomatic Bacteriuria in Pregnant Women - Study at a Tertiary Maternity care Hospital in Hyderabad, India. Int.J.Curr.Microbiol.App.Sci. 7(05): 1133-1142. doi: https://doi.org/10.20546/ijcmas.2018.705.138 